\title{
SNS Accumulator Ring Extraction Fast Kicker Modulator Initial Simulation
}

BNL/SNS TECHNICAL NOTE

NO. 051

Jianlin Mi

September 25, 1998

ALTERNATING GRADIENT SYNCHROTRON DEPARTMENT BROOKHAVEN NATIONAL LABORATORY

UPTON, NEW YORK 11973 


\title{
SNS Accumulator Ring Extraction Fast Kicker Modulator Initial Simulation
}

\author{
Jianlin Mi \\ AGS Department, \\ Brookhaven National Laboratory
}

September 25, 1998

\section{Introduction}

The fast kicker is used for extracting the beam, from the accumulator ring, in a single turn taking place in less than one beam revolution period of approximately $800 \mathrm{nS}$, very soon after the injection stacking process is completed. The accumulated beam will have a gap of $250 \mathrm{nS}$ to enable the magnetic field in the fast kicker to rise its extraction level within this gap. The fast kicker system consists of eight or more sections of ferrite core magnets. A pulse-forming network (PFN) is discharged into a single - turn ferrite core magnet by a fast ceramic thyratron, which is trigger by a ring radio frequency (rf) synchronized time trigger.

\section{Kicker requirements}

The requirements for the SNS extraction kicker are given in the SNS Design Report. section 5.11 (WBS 1.5.9). The main parameters are:

Vert deflection angle $\quad 16.8 \mathrm{mrad}$

$\operatorname{Gap}(\mathrm{H} \times \mathrm{V}) \quad 11.5 \mathrm{~cm} \times(12.9 \sim 15.4 \mathrm{~cm})$

Length of $\mathrm{F}_{\mathrm{e}}$ section $\quad 37 \mathrm{~cm} \sim 44 \mathrm{~cm}$

\section{Kicker magnet initial electric parameters}

For an eight (8) section kicker magnet, the following parameters are obtained.

$\begin{array}{lcc}\text { Kicker magnet inductance } & 1.1 & \mu \mathrm{H} \\ \text { Peak current } & 2.8 & \mathrm{kA} \\ \text { Pulse repetition rate } & 60 & \mathrm{~Hz} \\ \text { Rise time } & 200 & \mathrm{nS} \\ \text { Pulse flattop } & 600 & \mathrm{nS}\end{array}$


Fall time

Magnet sections

Re- charging time $12 \sim 14 \quad \mathrm{mS}$

\section{Kicker modulator simulation}

The simulation of the fast kicker modulator consists of a pulse-forming network (PFN), a switch $(\mathrm{SW})$, kicker inductor $\left(\mathrm{L}_{\mathrm{k}}\right)$ and a resistor $(\mathrm{R})$. The PFN is a equal capacitance pulse forming network which consists of twenty LC sections. The impedance of the PFN is $6 \Omega$. The simulation parameters are following:

$\begin{array}{lll}\text { PFN section } & 20 & \\ \text { Load inductance: } \mathrm{L}_{\mathrm{K}} & 1.10 & \mu \mathrm{H} \\ \text { Load resistance } \mathrm{R} & 6 & \Omega \\ \text { PFN capacitance } \mathrm{C}_{0} & 4.15 & \mathrm{nF} \\ \text { PFN inductance } \mathrm{L}_{0} & 0.15 & \mu \mathrm{H} \\ \text { PFN impedance } \mathrm{Z}_{0} & 6 & \Omega \\ & & \\ \text { Charging voltage } & 34 & \mathrm{kV} \\ \text { Peak current } & 2.8 & \mathrm{kA} \\ \text { Rise time } & <200 & \mathrm{nS} \\ \text { Pulse flattop: } & 700 & \mathrm{nS}\end{array}$

This simulation waveform of the kicker magnet current is shown in Fig 1. The vertical scale is current $/ 100$ and the horizontal scale is simulation time in $\mu \mathrm{sec}$. The peak current shown is 2845 Amperes. 


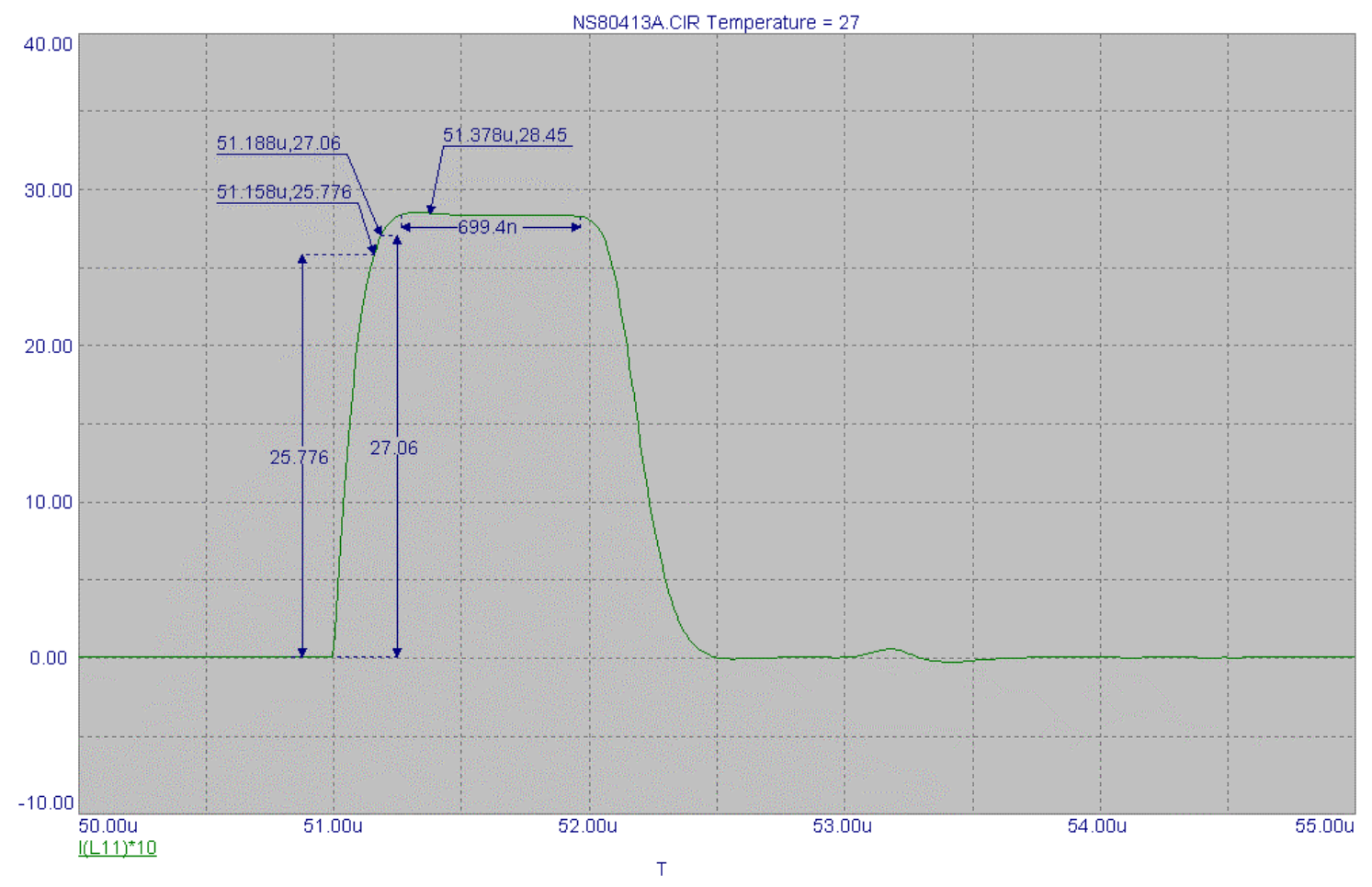

